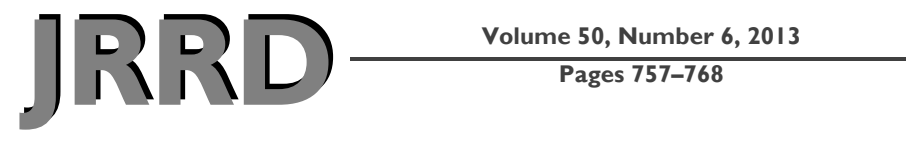

\title{
Development of a mild traumatic brain injury-specific vision screening protocol: A Delphi study
}

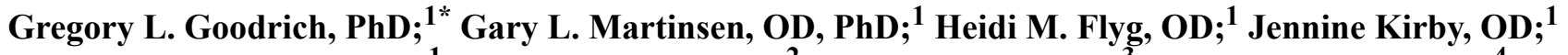
Steven M. Asch, MD, MPH; ${ }^{1}$ Karen D. Brahm, OD ${ }^{2}$ John M. Brand, OD ${ }^{3}$ Diana Cajamarca, OD $;^{4}$ Jenette L. Cantrell, OD ${ }^{5}$ Theresa Chong, OD ${ }^{6}{ }^{6}$ John A. Dziadul, OD; ${ }^{7}$ Barbara J. Hetrick, OD ${ }^{8}$ Michael A. Huang, OD; ${ }^{9}$ Carolyn Ihrig, OD ${ }^{10}$ Shanida P. Ingalla, OD; ${ }^{1}$ Bradley R. Meltzer, OD; ${ }^{11}$ Chrystyna M. Rakoczy, OD; ${ }^{12}$ Ashley Rone, OD; ${ }^{13}$ Elliot Schwartz, OD; ${ }^{14}$ Jane E. Shea, OD ${ }^{15}$ ${ }^{1}$ Department of Veterans Affairs (VA) Palo Alto Health Care System, Palo Alto, CA; ${ }^{2}$ William S. Middleton Memorial Veterans Hospital, Madison, WI; ${ }^{3}$ VA Salt Lake City Health Care System, Salt Lake City, UT; ${ }^{4}$ West Palm Beach VA Medical Center (VAMC), West Palm Beach, FL; ${ }^{5}$ Bay Pines VA Healthcare System, Bay Pines, FL; ${ }^{6}$ VA Southern Nevada Healthcare System, North Las Vegas, NV; ${ }^{7}$ Viera VA Outpatient Clinic, Viera, FL; ${ }^{8}$ Jonathan M. Wainwright Memorial VAMC, Walla Walla, WA; ${ }^{9}$ VA Mission Valley Clinic, San Diego, CA; ${ }^{10}$ VA Western New York Healthcare System, Buffalo, NY; ${ }^{11}$ Northport VAMC, Northport, NY; ${ }^{12}$ James A. Haley Veterans' Hospital, Tampa, FL; ${ }^{13}$ Lexington VAMC, Lexington, KY; ${ }^{14}$ VA New York Harbor Healthcare System, New York, NY; ${ }^{15}$ VA St. Louis Health Care System, St. Louis, $M O$
\end{abstract}

\begin{abstract}
Although traumatic brain injury (TBI) can happen to anyone at any time, the wars in Iraq and Afghanistan have brought it renewed attention. Fortunately, most cases of TBI from the recent conflicts are mild TBI (mTBI). Still, many physical, psychological, and social problems are associated with mTBI. Among the difficulties encountered are oculomotor and vision problems, many of which can impede daily activities such as reading. Therefore, correct diagnosis and treatment of these mTBI-related vision problems is an important part of patient recovery. Numerous eye care providers in the Department of Veterans Affairs, in military settings, and in civilian practices specialize and are proficient in examining patients who have a history of TBI. However, many do not have this level of experience working with and treating patients with mTBI. Recognizing this, we used a modified Delphi method to derive expert opinions from a panel of 16 optometrists concerning visual examination of the patient with mTBI. This process resulted in a clinical tool containing 17 history questions and 7 examination procedures. This tool provides a set of clinical guidelines that can be used as desired by any eye care provider either as a screening tool or adjunct to a full eye examination when seeing a patient with a history of mTBI. The
\end{abstract}

goal of this process was to provide optimal and uniform vision care for the patient with mTBI.

Key words: accommodation, binocular vision, consensus, convergence insufficiency, Delphi method, mild traumatic brain injury, oculomotor, optometrist, traumatic brain injury, visual symptoms.

\footnotetext{
Abbreviations: $\mathrm{BV}=$ binocular vision, $\mathrm{CI}=$ convergence insufficiency, $\mathrm{LOC}=$ loss of consciousness, $\mathrm{mTBI}=$ mild traumatic brain injury, PCS $=$ postconcussion syndrome, $\mathrm{PRC}=$ Polytrauma Rehabilitation Center, TBI = traumatic brain injury, VA $=$ Department of Veterans Affairs, VHA = Veterans Health Administration.

*Address all correspondence to Gregory L. Goodrich, PhD; VA Palo Alto Health Care System, 795 Willow Rd, Bldg T365, Menlo Park, CA 94025; 650-493-5000, ext 24640; fax: 650-614-9955. Email: Gregory.Goodrich@va.gov http://dx.doi.org/10.1682/JRRD.2012.10.0184
} 


\section{INTRODUCTION}

Mild traumatic brain injury (mTBI) and concussion are interchangeable terms referring to mild brain injury arising from external forces [1]. By definition, mTBI is a form of neurotrauma. Traumatic brain injury (TBI) is diagnosed as mild, moderate, or severe based on the events that occur directly following the insult. These events include loss of consciousness (LOC), posttraumatic amnesia, disorientation, or other neurological problems. If an individual sustained head trauma without any of these accompanying signs or symptoms, the diagnosis of TBI would not be made. The diagnosis of mTBI usually requires one or more of the following: Glasgow Coma Scale score of 13 to 15 , LOC lasting $<30 \mathrm{~min}$, posttraumatic amnesia lasting $<24 \mathrm{~h}$, and/or any alteration in mental state immediately following the event [23]. Standard radiological techniques, magnetic resonance imaging and computed tomography, usually show no associated abnormalities in mTBI [4]. TBI with signs or symptoms exceeding those of mTBI is termed moderate or severe.

The symptoms used to diagnose TBI at the time of injury (e.g., LOC) are not the same as those that may occur a few days or more after the injury. Postconcussion syndrome (PCS) refers to the spectrum of symptoms that can arise after TBI and is a frequent reason for doctor visits [5-6]. The symptoms of PCS may persist for days, months, or years after the injury and often include fatigue, dizziness, headache, memory problems, and poor concentration. Unfortunately, many persons who have incurred TBI go on to have additional problems, including medical, psychological, and social problems; problems with academics and with alcohol abuse; and numerous others [7-8].

Among the many issues that can arise post-TBI, as part of PCS, are problems related to the eyes and vision [6]. Blurred vision, light sensitivity (photophobia), and diplopia have been reported [9-13]. These can occur subsequent to TBI from all causes, regardless of severity. Problems with binocular vision (BV), extraocular muscle function, and the accommodative system have also been found at relatively high frequencies [10-12]. These and other TBI-related vision problems have the potential to affect daily functioning in affected patients. For example, reading problems from convergence or accommodative deficiencies can negatively affect educational endeavors. In addition, sensitivity to light may cause discomfort or headaches. These examples illustrate the potential negative effect of TBI on vision and underscore the importance of correctly evaluating and treating these problems.

The recent conflicts in Iraq and Afghanistan have brought increased awareness to TBI. It is estimated that since the beginning of hostilities, more than 262,065 servicemembers have sustained a TBI [14]. However, TBI is not exclusive to the military, and approximately 1.7 million persons from all professions and lifestyles incur TBI in the United States every year [15]. Many military servicemembers and veterans with moderate or severe TBI also have physical injuries and are seen in polytrauma treatment facilities in the Department of Veterans Affairs (VA) system of care. Polytrauma is defined as having injuries to multiple body parts and organs, one of which may be life threatening [16]. Patients with polytrauma usually have access to advanced eye care as part of their treatment plans. In fact, Veterans Health Administration (VHA) Directive 2008-065 requires that any patient who has been admitted to a Polytrauma Rehabilitation Center (PRC) with a definitive diagnosis of TBI be referred to optometry or ophthalmology for a comprehensive TBIspecific ocular health and visual functioning examination [17]. However, there may be over 180,000 Active Duty servicemembers and veterans with mTBI resulting from recent overseas conflicts that do not have polytrauma and therefore may not have formal access to eye care services. Some of these patients may be referred to optometry or ophthalmology if a visual or eye-related complaint is made to their primary care provider, but many of those who do not complain of vision problems may not be referred for eye care. In addition, many patients with mTBI may obtain appointments at locations where the eye care professionals are not as familiar with examining patients with mTBI as those within the PRC. This study was undertaken to propose clinical guidelines, or a baseline screening tool, for eye care providers in the vision evaluation of patients with mTBI.

To produce these guidelines, we employed the Delphi consensus method. The RAND Corporation developed the Delphi method in the 1950s under the auspices of the U.S. Air Force [18]. It was named Delphi after the Oracle of Delphi from Greek mythology, who purportedly had the ability to forecast the future [19]. One of its early uses was to get expert estimates of the amount of damage that might be expected from a nuclear attack on the United States by the Soviet Union [20]. From these somewhat ominous origins arose a consensus-building 
tool that is now employed in numerous fields, including healthcare [21]. It is often used to provide data and guidance in situations in which gathering empirical data would be impractical or cost prohibitive.

The Delphi method has a structured format, including [22-23]-

1. Enrollment of expert participants.

2. Anonymity or pseudo-anonymity of the participants. The participants are frequently unknown to one another but not to the steering committee.

3. Iterative surveys. Survey questions are re-asked after the participants receive previous survey results.

4. Feedback of results. Participants receive the group statistics prior to the next survey round and they may use the results to change or reinforce their original answer to a question.

5. Consensus definition. This varies among studies, ranging from 51 to over 80 percent agreement required for consensus. It is open to controversy because some researchers define the consensus requirement after seeing the survey results [23].

Most researchers employ a "modified" Delphi method when conducting studies, because the exact steps required within the format can be tailored to fit the needs of the research [24-25]. For example, the number of participants enrolled as experts in Delphi research has varied from less than 10 to over 1,500 [26].

There are many benefits to using the Delphi method to answer specific research questions. Dalkey and Helmer, early pioneers in Delphi methodology, summarize its benefits as, "The method employed in the experiment appears to be more conducive to independent thought on the part of the experts and to aid them in the gradual formation of a considered opinion" [20]. The Delphi method can be used to provide information without the participants meeting face-to-face as would occur in a committee meeting. This not only saves time and cost but also avoids many of the pitfalls inherent to assembled meetings. One drawback to face-to-face meetings is that dominant individuals, persons with strong personalities, or those with seniority may overly influence the proceedings, and thereby, the output [26]. By employing anonymity, iterative questions, and feedback of previous results, the Delphi method delivers group results without many of the disadvantages of participants meeting directly.

Over the years, researchers in healthcare have employed the Delphi method to inquire into a variety of diagnostic and treatment issues [27]. In a 1976 study, Schoenbaum et al. elicited input from 15 experts to analyze the costs, benefits, and alternatives of implementing a vaccination program similar to that established for the recent swine influenza outbreak to determine the most effective strategy for future epidemics [28]. In a 1973 report, Milholland et al. recruited 14 general surgeons as expert participants to estimate human morbidity and mortality expectations from injuries in an animal model [29]. Ferri et al. used the Delphi method to obtain evidence on the global prevalence of dementia from known data and tendencies [30]. The eye care profession has also used the Delphi method to derive solutions to research questions. Stelmack et al. used a modified Delphi method to develop the VA Low Vision Visual Functioning Questionnaire and to address its use as a tool for low vision patient evaluation [31]. In addition, the Delphi method has also been used to develop and evaluate metrics for diabetic retinopathy and macular edema [32], thyroid eye disease [25], and glaucoma [33]. A 2003 study by Tobacman et al. supported the validity of using a modified Delphi method to assess the appropriateness of clinical procedures in eye care [34]. These researchers compared visual acuity after cataract surgery with appropriateness indicators rated by nine physicians. They found that at 4 months after surgery, acuity increased in 91 percent of 478 cases for which the panel rated the indicators for surgery as appropriate. They also cautioned that the process is imperfect because a small percentage of patients for which the indicators were rated as appropriate had acuity decreases.

We used the Delphi method in this study to propose a set of clinical guidelines for use by optometrists and other eye care providers when screening or examining patients with mTBI. The guidelines can supplement routine eye examinations or screenings. They are intended to improve the consistency of eye and vision examinations, thereby increasing the quality of eye care provided to patients with mTBI. In turn, this could enhance research on vision and mTBI that could be used to devise new examination methods and treatments for vision problems occurring in the mTBI population.

\section{METHODS}

We employed a modified Delphi method to elicit opinions from a team of expert participants regarding 
vision evaluation of the patient with mTBI, including case history questions and examination procedures.

\section{Steering Committee}

The steering committee was made up of four of the authors (G. G., G. M., H. F., and J. K.). The role of the committee was to define the qualifications of expert participants, design the surveys, establish the survey parameters, and analyze the results.

\section{Expert Participants}

An initial questionnaire was sent to optometrists employed in the VA to determine how often they see patients with mTBI and to assess their interest in participating in research on vision and mTBI. The survey was sent to 608 VA optometrists, and 213 responded, yielding a 35 percent response rate. Most of the respondents (78.2\%) were full-time staff, and 71.1 percent indicated that they examine patients with mTBI. Of the respondents, 67 indicated that they would be interested in participating in future research on vision and mTBI. A follow-up questionnaire sent to these 67 optometrists contained more specifics about the research and asked for demographic information. We received 42 responses from these 67 individuals $(63 \%)$. Of those that responded, 24 indicated that they were still interested in participating in the research. The steering committee compared demographic information gathered from these 24 optometrists with pre-established inclusion criteria and pared the final list of participants to 16 . The inclusion criteria were-

1. Knowledge of and experience in the examination and treatment of patients with mTBI.

2. Full-time VA employees. Full-time optometrists are more likely to have sufficient time to devote to the project.

3. A history of research involvement preferred. This selected for participants who were familiar with research protocols and timelines, as well as meeting project deadlines.

4. Optometrists from a variety of practice settings. This criterion allowed for an expert panel representing a variety of clinic settings and practice locations.

\section{Survey Development}

The steering committee sent an informational email with a copy of VHA Directive 2008-065 [17] to each expert participant prior to any surveys. The email also conveyed mTBI examination-specific conditions, or assumptions, for this study. These assumptions were necessary to prevent the scope of the study from becoming too large and to provide direction when answering survey questions. The assumptions were-

1. The patient was definitively diagnosed with mTBI.

2. This is baseline testing. Follow-up or referral may be required based on the results.

3. The patient has no visual or ocular complaints (normal history).

4. The examination can be accomplished in one appointment slot.

5. No specialty clinic equipment or methods are required. The steering committee wrote the survey questions utilizing examination questions and templates submitted by the participants. Additional sources consulted were VHA Directive 2008-065 [17] and pertinent literature (e.g., Brahm et al. [10]).

To initiate each survey round, an email was sent to each participant with a link to the survey (SurveyMonkey.com). There were two surveys, a patient history survey and an examination procedures survey, each administered in two rounds. Survey questions concerning routine vision examination procedures such as visual acuity were not included. Instead, the questions focused on common mTBI-specific problem areas. To maximize participant responses, two reminders were emailed to the participants for each survey round.

Round 1 of the history survey had 40 questions organized into six categories addressing (1) general mTBI history, (2) mTBI injury history, (3) mTBI sensory history, (4) mTBI eye injury and pain history, (5) mTBI vision history, and (6) mTBI reading history (see Appendix 1, available online only, for all questions). The five possible responses to each question were (1) strongly disagree, (2) disagree, (3) neutral, (4) agree, and (5) strongly agree. Participants were encouraged to make comments about any of the issues addressed in the survey, to suggest changes to questions, and to suggest alternate questions.

The examination procedures survey had 43 items addressing eye and vision testing techniques organized into five categories covering (1) extraocular motility and BV testing, (2) accommodation testing, (3) saccadic and fixation testing, (4) near point of convergence testing, and (5) other testing. The "other testing" category had seven questions addressing items such as color vision, contrast sensitivity, and glare sensitivity testing (see Appendix 2, available online only, for all items). 
The steering committee established the requirements for acceptance or rejection of a survey question prior to sending out the surveys. Any question with 80 percent or more of the responses marked strongly agree or agree was accepted [35]. Questions with less than 50 percent of the responses rated strongly agree or agree were rejected. All questions accepted or rejected in the first round were removed from further consideration. Questions with less than 80 but over 50 percent agreement were re-asked. Before sending out round 2 surveys, the results of the first round were provided to the participants. The questions to be re-asked were accompanied by a chart with distribution frequencies of the round 1 responses. In addition, comments submitted in round 1 were shared with all participants. Participants could change their answers in round 2 after reviewing round 1 results if they wished. Any question not accepted in either round 1 or 2 was rejected.

An optional questionnaire that was not part of the Delphi rounds was sent to the participants after the Delphi rounds were completed. These questions asked for details on how participants conducted procedures and tests that were accepted in the examination procedures survey.

\section{RESULTS}

\section{Expert Participants}

Table 1 shows the characteristics of the 16 enrolled optometrists. All of the expert participants had experience working with patients with TBI, all but one was employed full-time by the VA, and half had prior research experience. Importantly, the participants represented multiple subspecialties, including general optometry, BV, low vision, polytrauma, and others. Diversity was also evident in the participants' practice locations.

\section{History Survey}

Of the expert participants, 13 of $16(81 \%)$ responded to round 1 of the history survey. The survey had 40 questions addressing what history is important to obtain from patients with mTBI during an initial eye examination. In round 1,17 questions were accepted and 2 were rejected. After reviewing the results and comments from round 1, participants were asked to complete round 2, and 12 of $16(75 \%)$ participants responded. The 20 questions not accepted or rejected in round 1 were re-asked in round 2. Additionally, one new question, suggested by a participant, was asked. No additional questions were accepted in round 2. Thus, the final list of history questions had 17 items (Table 2).

Table 1.

Demographic information of participants.

\begin{tabular}{lccccc}
\hline $\begin{array}{c}\text { Participant } \\
\text { mTBI Examinations } \\
(\mathbf{m o})\end{array}$ & FT/PT & Setting & $\begin{array}{c}\text { Research } \\
\text { Experience }\end{array}$ & Location \\
\hline 1 & $6-10$ & FT & Op & Yes & Wisconsin \\
2 & $1-5$ & FT & Op, LV & Yes & Utah \\
3 & $1-5$ & FT & LV, BV & No & Florida \\
4 & $4-8$ & FT & Op & No & Florida \\
5 & $1-5$ & FT & LV & No & Nevada \\
6 & $1-5$ & FT & Op & Yes & Florida \\
7 & $\geq 11$ & FT & PRC, PNS & Yes & California \\
8 & $1-5$ & FT & Op & Yes & Washington \\
9 & $\geq 11$ & FT & LV & Yes & California \\
10 & $1-5$ & FT & PS & No & New York \\
11 & $\geq 11$ & FT & PRC, PNS, Op & Yes & California \\
12 & $6-10$ & PT & CB & No & New York \\
13 & $\geq 11$ & FT & PRC, PNS & No & Florida \\
14 & $\geq 11$ & FT & Op & No & Kentucky \\
15 & $1-5$ & FT & Op & Yes & New York \\
16 & $0.5-1$ & FT & Op, LV & No & Missouri \\
\hline BV= Binocular Vision Clinic, CB $=$ Center of Balance Clinic, FT $=$ full-time, LV = Low Vision Clinic, mTBI = mild traumatic brain injury, Op = general optometry \\
clinic, PNS = Polytrauma Network Center, PRC = Polytrauma Rehabilitation Center, PS = Polytrauma Support Clinical Team, PT = part-time.
\end{tabular}


The history survey was divided into six categories based on the information the question addressed. The categories were for organizational purposes and not meant to convey any significance about the questions each category contained. Table 2 shows that one or more questions from each of the six categories were accepted. The two categories directly related to vision, mTBI vision history and reading history, had the most questions accepted.

\section{Examination Procedures Survey}

The examination procedures survey contained 43 questions about the baseline tests that are important during initial eye/vision examinations of patients with mTBI. Round 1 responses were received from 12 of the 16 (75\%) expert participants; of the items, 3 were accepted and 18 were rejected. In round 2, participants were re-asked 21 questions. Two questions about saccadic testing from round 1 were combined into one question in round 2. Based on participant feedback, three questions that ended with the phrase "is absolutely required for every mTBI patient" were changed to end with "are important to test on every mTBI patient." Of the participants, 13 of $16(81 \%)$ responded to round 2 and four additional examination procedures items were accepted. Table 3 shows the seven accepted examination procedures.

It is important to be aware that many routine eye examination techniques, such as visual acuity and ocular health assessment, were not included in the examination procedures survey. All of the accepted items in Table 3 involve testing oculomotor, binocular, and/or accommodative functions. Four examination procedure items had 77 percent of the participants rate the test as important, but these are not included in Table 3 because the a priori requirement was 80 percent. These four items were stereopsis (depth perception) testing, light/glare sensitivity testing, fixation/nystagmus testing, and testing phorias beyond cover testing (see Appendix 2, available online only). If one more of the respondents had rated any of these tests as important, it would have been included in Table 3.

Table 2.

Accepted history questions. In survey, each question ended in phrase "is an important question to ask the mTBI patient." Category designations include (1) General TBI History, (2) TBI Injury History, (3) TBI Sensory History, (4) TBI Eye Injury/Pain, (5) TBI Vision History, and (6) TBI Reading History.

\begin{tabular}{|c|c|}
\hline Question & Category \\
\hline $\begin{array}{l}\text { Did you have any neurological problems or symptoms before your TBI (MS, stroke, brain tumor, severe } \\
\text { headaches, other)? }\end{array}$ & 1 \\
\hline Did you lose consciousness during or after your TBI incident? & 2 \\
\hline Were you disoriented or confused during or after your TBI incident? & 2 \\
\hline Do you cover or close one eye at times since your injury? & 4 \\
\hline Have you noticed a change in your vision since your injury? & 5 \\
\hline Are you more sensitive to light, either indoors or outdoors, since your injury? & 5 \\
\hline Have you had any double vision since your injury?* & 5 \\
\hline Do you lose your place while reading more now than before your injury? & 6 \\
\hline How long can you read continuously before you need to stop? ${ }^{*}$ & 6 \\
\hline Do you get headaches during/after reading more now than before your injury? & 6 \\
\hline Do you have more difficulty remembering what you have read now than before your injury? & 6 \\
\hline
\end{tabular}


Table 3.

Seven accepted examination procedures. Each item ended with phrase "is/are important to test on every mTBI patient." Category designations include (1) EOM/BV Tests, (2) Accommodation Tests, (3) Saccadic/Fixation Tests, and (4) NPC Tests.

\begin{tabular}{lc}
\hline \multicolumn{1}{c}{ Procedure } & Category \\
\hline Distance Cover Test $^{*}$ & 1 \\
Near Cover Test $^{*}$ & 1 \\
Versions (EOMs) and/or Pursuit & 1 \\
Accommodation & 2 \\
Saccades & 3 \\
NPC & 4 \\
Repeated NPC & 4
\end{tabular}

*Includes both unilateral and alternate cover testing.

$\mathrm{BV}=$ binocular vision, $\mathrm{EOM}=$ extraocular motility, $\mathrm{mTBI}=$ mild traumatic brain injury, NPC = near point of convergence.

After the completion of the Delphi rounds, the steering committee sent participants an optional survey requesting information on the specific methods they each used when conducting the accepted examination procedures. We asked these questions because the accepted examination procedures (Table 3) do not include any specific testing methods. Ten participants completed the optional survey, and Table 4 summarizes their responses. As shown, targets used for cover testing at distance varied from Snellen acuity chart letters and projected dots to a number on a wall clock. Reduced Snellen letters or the printing on a pen or pencil were most commonly used as targets for near cover testing. Accommodation can be tested in pre-presbyopia using a number of different methods [36], and this is reflected in Table 4. In all cases, a small letter or a small acuity chart served as targets. Reported cutoff ages for testing accommodation ranged from 35 to 50 years. Testing methods for the other accepted procedures also varied among the practitioners.

\section{DISCUSSION}

We undertook this study with the goal of delivering a clinical tool, or a set of clinical guidelines, that could be used by eye care providers when examining patients with mTBI. For this project, each of the expert contributors was asked to make certain assumptions about the patients with mTBI under consideration. One assumption was that the patient was asymptomatic and another was that each test conducted thus far in a hypothetical eye examination was normal. The reason for these assumptions was that a
Table 4.

Summary of targets (and tests for accommodation and saccades) participants reported using when conducting accepted examination procedures.

\begin{tabular}{|c|c|}
\hline Examination Procedure & Test \\
\hline Distance Cover Test: Target & $\begin{array}{l}\text { Isolated letter two lines above } \\
\text { best acuity } \\
\text { Muscle light/dot } \\
\text { Projector fixation target } \\
\text { Number on wall clock }\end{array}$ \\
\hline Near Cover Test: Target & $\begin{array}{l}\text { Accommodative target } \\
\text { 20/40 letter on ball on stick } \\
\text { Penlight } \\
\text { Cube target on stick (Lang } \\
\text { cube) } \\
\text { Tip of pen } \\
\text { Letters on pen/pencil }\end{array}$ \\
\hline Versions/Pursuit: Target & $\begin{array}{l}\text { Detailed near target } \\
\text { Penlight/transilluminator } \\
\text { Tip of pen } \\
\text { Bead on stick } \\
\text { Fingers } \\
\text { Pencil eraser }\end{array}$ \\
\hline $\begin{array}{l}\text { Accommodation: Test } \\
\text { and/or Target }\end{array}$ & $\begin{array}{l}\text { NRA/PRA with letter two lines } \\
\text { above near acuity } \\
\text { Pull away test with letter two } \\
\text { lines above near acuity } \\
\text { Line of letters patient can see } \\
\text { Push-up test with small near } \\
\text { chart on stick } \\
\text { Flippers with } \pm 2.00 \text { flippers, } \\
\text { 20/40 letter } \\
\text { Binocular cross-cylinder } \\
\text { Small near chart }\end{array}$ \\
\hline Saccades: Test and/or Target & $\begin{array}{l}\text { Two detailed near targets } \\
\text { Fingers } \\
\text { Beads on sticks } \\
\text { 20/40 letters } \\
\text { Tip of pen } \\
\text { Red/green Avery dots }\end{array}$ \\
\hline $\begin{array}{l}\text { Near Point of Convergence: } \\
\text { Target }\end{array}$ & $\begin{array}{l}\text { Reduced Snellen letter, } 20 / 40 \\
\text { letter } \\
\text { Tip of pen } \\
\text { Small near chart } \\
\text { Accommodative target } \\
\text { Penlight } \\
\text { Lang cube }\end{array}$ \\
\hline \multicolumn{2}{|c|}{ NRA $=$ negative relative accommodation, $\mathrm{PRA}=$ positive relative accommodation } \\
\hline
\end{tabular}

multitude of examination and treatment pathways could be pursued following a reported visual symptom or abnormal test result. For example, the vision examination 
steps for a post-mTBI patient who complains of diplopia and headaches after reading would be different from those for an asymptomatic patient. Additionally, all participants knew that any positive finding would trigger additional questions, additional testing, follow-up examination, and/or referral.

The results of this research reflect the importance of the history in eye examinations of patients with mTBI because 17 history questions were accepted. Evidence from quantitative medical research supports this finding. A 1992 study by Peterson et al. involving 4 internists and 80 new medical outpatients at the University of Utah found that the history led to the final diagnosis 76 percent of the time [37]. The diagnosis was made from the physical examination in 13 percent of the patients and from laboratory testing in 11 percent of the patients. Similar results were also reported in a 1975 study by Hampton et al. [38]. These results confirm the essential role of the history in medical examinations with the understanding that other testing is often required to confirm a diagnosis.

The 17 accepted history questions (Table 2) covered a range of issues concerning what was present before and what happened after the mTBI event, including neurological history, specifics about the TBI-inducing event, and ocular injuries. However, the majority of questions focused on visual and reading symptoms. Supporting this finding is evidence that patients with TBI have high frequencies of vision and reading problems [10-11,39]. Many of these problems might be related to abnormalities in BV function and estimates of binocular deficiencies following TBI of all severities are high, ranging from 30 to over 60 percent $[10,40]$. By comparison, BV problems in general eye care settings have been reported in only about 22 percent of patients presenting with visual complaints [41-42]. Our findings, and those of others, reinforce the need to address $\mathrm{BV}$ and reading issues during the history portion of vision examinations for patients with mTBI. Inquiring about light sensitivity in patients with mTBI was also found to be important in the current study, and prior research has shown it to be a common complaint in patients with TBI $[9,11,40]$.

All seven items selected in the mTBI examination procedures survey are measures of oculomotor, accommodative, and BV functions. Several previous studies of vision changes after TBI support our findings and are summarized in Table 5. Oculomotor function and BV deficits are common in and problematic for patients with TBI, indicating that thorough testing is warranted. For example, proper functioning of the accommodative system in pre-presbyopes and of the saccadic system in all persons is required for efficient reading [43-44]. In turn, good reading skills are required for many daily activities, including educational pursuits. Convergence insufficiency (CI) is associated with a number of symptoms, including headaches, eye fatigue, and asthenopia, and is estimated to be prevalent in 2.0 to 8.5 percent of the general population [45-46]. However, the rates of CI from recent studies of patients with TBI are much higher (Table 5). In a related study, Cohen et al. examined 72 patients with TBI 3 years after their injury and found CI in 42 percent of the cases, indicating the persistence of the problem [47]. Reflecting the potential seriousness of the condition, CI in these patients was significantly associated with cognitive disturbance and failure to find work.

The mTBI vision examination procedures agreed upon by the participants do not include any specific testing methods or techniques. For instance, accommodation can be tested with a number of techniques [48], and participants reported using several different methods. Our finding that the optometrists did not reach agreement on specific oculomotor and BV testing methods does not detract from the importance of conducting the testing in mTBI. In 2011, while this study was being conducted,

Table 5.

Vision dysfunctions in patients with traumatic brain injury (TBI) from recent studies.

\begin{tabular}{|c|c|c|c|c|c|}
\hline \multirow{2}{*}{ Study } & \multicolumn{5}{|c|}{ Dysfunction (\%) } \\
\hline & Reading & Convergence & Accommodation & Strabismus & Pursuit/Saccades \\
\hline Goodrich et al., 2007 [39] & 61 & 30 & 22 & - & 20 \\
\hline Brahm et al., 2009 [10] & 87 & 48 & 49 & 7 & 23 \\
\hline Stelmack et al., 2009 [11] & 50 & 28 & 47 & 8 & 6 \\
\hline Ciuffreda et al., 2007 [12] & - & 42 & 41 & 25 & 39 \\
\hline Capó-Aponte et al., 2012 [40] & 65 & 55 & 65 & 0 & 60 \\
\hline
\end{tabular}


Ciuffreda and Ludlam published an editorial addressing targeted high-yield objective clinical tests for the mTBI population [49]. The clinical tests proposed in that editorial overlap considerably with those developed in this Delphi study and provide clinicians with valuable clinical tools not specified by our methodology.

As with all research conducted using the Delphi method, bias is possible and may be problematic $[21,50]$. The first potential source of bias was in recruiting the panel of experts. Since participation was voluntary, inclusion may have been biased toward those who were interested in the research area and its outcomes. It is unknown whether the participants' motivations affected their choices. It is also unknown whether other experts who chose not to participate would have provided similar answers. Research has shown that panel makeup may influence the results in Delphi research. A study examining the appropriateness of clinical quality indicators that enrolled primary care physicians and primary care managers as expert panel members found that the managers rated the indicators higher than the physicians did [51]. Additionally, physicians who received Delphi round feedback from both physicians and managers rated indicators higher in round 2 than physicians who received feedback from other physicians only. Studies such as this demonstrate that caution is needed when interpreting results of Delphi research. Other sources of bias in Delphi research undoubtedly occur, although adherence to predefined research parameters, as was done in this study, should lessen its effect.

The Delphi method delivers results in the form of expert opinions $[23,28]$. Therefore, it gives "an answer," but not necessarily "the answer" to the question under consideration, which, in this study was, "What vision examination tests are important after mTBI?" The clinical guidelines produced by this effort can be modified to suit individual patient needs. Specifically, those items in Appendix 2 (phorias, fixation/nystagmus, stereopsis, and light/glare sensitivity) could be included in the examination procedures, resulting in a slightly longer, but more comprehensive, 11-item testing set.

Finally, the diagnosis of mTBI, the repercussions of the diagnosis, the symptoms arising from the injury, and the terminology associated with the condition are complicated and controversial $[3,52]$. The overlap of PCS symptoms with those of posttraumatic stress disorder can be especially troublesome and may cause difficulty in determining appropriate treatment and referral for patients who have sustained mTBI. Even so, as more research is brought forward in this area, it is becoming increasingly clear that vision and ocular problems frequently occur in persons with a history of mTBI and can have negative consequences on patient functioning and quality of life $[12,53]$.

\section{CONCLUSIONS}

Abnormal oculomotor and BV function findings and subjective complaints about vision are common sequelae of TBI, including mTBI [10-12,39]. Diagnosing and addressing these visual problems are important parts of the pathway of care for patients with mTBI. A number of eye care providers in VA, military settings, and civilian practices specialize and are proficient in the examination of patients who have a history of TBI. However, many eye care providers do not have this level of experience working with and treating patients with mTBI. Additionally, even among the specialists, the exact steps to take, the questions to ask, and the testing to conduct during the mTBI patient examination varies from one provider to another. Empirical research might reveal the best questions and testing for examining the patient with mTBI but the research effort would be lengthy and expensive. The current study employed an alternate technique, the Delphi method, to provide answers, albeit not necessarily the only answers, to these issues. Input from 16 expert participants, a series of surveys, and an 80 percent agreement minimum yielded 17 history questions and 7 examination procedures that can be utilized in the mTBI patient vision examination. Any eye care provider can augment his or her vision examination with these questions and procedures, if desired, when seeing a patient with mTBI. These findings can also be modified for use when and if a provider sees fit. Besides serving as a set of guidelines, the tool developed here can serve as an education source for anyone interested in mTBI and vision. Ultimately, the goal of this process was to help ensure optimal and uniform vision care for every patient, including those with mTBI.

\section{ACKNOWLEDGMENTS}

\section{Author Contributions:}

All authors contributed significantly to the writing and editing of the manuscript.

Study design: G. L. Goodrich, G. L. Martinsen, H. M. Flyg, J. Kirby. Steering committee: G. L. Goodrich, G. L. Martinsen, H. M. Flyg, J. Kirby. 
Expert advisors and participants: S. M. Asch, K. D. Brahm, J. M. Brand, D. Cajamarca, J. L. Cantrell, T. Chong, J. A. Dziadul, B. J. Hetrick, M. A. Huang, C. Ihrig, S. P. Ingalla, B. R. Meltzer, C. M. Rakoczy, A. Rone, E. Schwartz, J. E. Shea.

Financial Disclosures: The authors have declared that no competing interests exist.

Funding/Support: This material was based on work supported by a VA Health Services Research \& Development QUERI (grant RRP 11008).

Institutional Review: Approval was obtained from the Institutional Review Board and the VA Palo Alto Health Care System Research and Development Committee prior to initiation of this research.

\section{REFERENCES}

1. Bigler ED. Neuropsychology and clinical neuroscience of persistent post-concussive syndrome. J Int Neuropsychol Soc. 2008;14(1):1-22. [PMID:18078527] http://dx.doi.org/10.1017/S135561770808017X

2. The Mild Traumatic Brain Injury Committee of the Head Injury Interdisciplinary Special Interest Group of the American Congress of Rehabilitation Medicine. Definition of mild traumatic brain injury. J Head Trauma Rehabil. 1993;8(3):86-87. http://dx.doi.org/10.1097/00001199-199309000-00010

3. Powell JM, Ferraro JV, Dikmen SS, Temkin NR, Bell KR. Accuracy of mild traumatic brain injury diagnosis. Arch Phys Med Rehabil. 2008;89(8):1550-55. [PMID:18597735]

4. Belanger HG, Vanderploeg RD, Curtiss G, Warden DL. Recent neuroimaging techniques in mild traumatic brain injury. J Neuropsychiatry Clin Neurosci. 2007;19(1):5-20. [PMID:17308222]

5. Mittenberg W, Canyock EM, Condit D, Patton C. Treatment of post-concussion syndrome following mild head injury. J Clin Exp Neuropsychol. 2001;23(6):829-36. [PMID:11910547] http://dx.doi.org/10.1076/jcen.23.6.829.1022

6. King NS. Post-concussion syndrome: clarity amid the controversy? Br J Psychiatry. 2003;183:276-78. [PMID:14519601] http://dx.doi.org/10.1192/bjp.183.4.276

7. TBI Community [Internet]. Resources and publications. Houston (TX): RRTC on Community Integration of Persons with Traumatic Brain Injury; 2013 [cited 2012 May 8]. Available from:

http://www.tbicommunity.org/resources/index.htm

8. Hoge CW, McGurk D, Thomas JL, Cox AL, Engel CC, Castro CA. Mild traumatic brain injury in U.S. Soldiers returning from Iraq. N Engl J Med. 2008;358(5):453-63. [PMID:18234750] http://dx.doi.org/10.1056/NEJMoa072972
9. Lew HL, Poole JH, Vanderploeg RD, Goodrich GL, Dekelboum S, Guillory SB, Sigford B, Cifu DX. Program development and defining characteristics of returning military in a VA Polytrauma Network Site. J Rehabil Res Dev. 2007; 44(7):1027-34. [PMID:18075959] http://dx.doi.org/10.1682/JRRD.2007.05.0073

10. Brahm KD, Wilgenburg HM, Kirby J, Ingalla S, Chang CY, Goodrich GL. Visual impairment and dysfunction in combat-injured servicemembers with traumatic brain injury. Optom Vis Sci. 2009;86(7):817-25. [PMID:19521270]

11. Stelmack JA, Frith T, Van Koevering D, Rinne S, Stelmack TR. Visual function in patients followed at a Veterans Affairs polytrauma network site: an electronic medical record review. Optometry. 2009;80(8):419-24.

[PMID:19635432]

http://dx.doi.org/10.1016/j.optm.2009.02.011

12. Ciuffreda KJ, Kapoor N, Rutner D, Suchoff IB, Han ME, Craig S. Occurrence of oculomotor dysfunctions in acquired brain injury: a retrospective analysis. Optometry. 2007;78(4):155-61. [PMID:17400136]

http://dx.doi.org/10.1016/j.optm.2006.11.011

13. Gironda RJ, Clark ME, Ruff RL, Chait S, Craine M, Walker R, Scholten J. Traumatic brain injury, polytrauma, and pain: challenges and treatment strategies for the polytrauma rehabilitation. Rehabil Psychol. 2009;54(3):247-58. [PMID:19702423] http://dx.doi.org/10.1037/a0016906

14. Defense and Veterans Brain Injury Center [Internet]. DoD worldwide numbers for TBI. Silver Spring (MD): DVBIC; 2013 [updated 2013 Feb 13; cited 2013 Jan 15]. Available from: http://www.dvbic.org/dod-worldwide-numbers-tbi

15. Centers for Disease Control and Prevention [Internet]. How many people have TBI? Atlanta (GA): CDC; 2013 [updated 2013 Mar 27; cited 2012 Jun 6]. Available from: http://www.cdc.gov/TraumaticBrainInjury/statistics.html

16. Polytrauma \& blast-related injuries. QUERI fact sheet. Minneapolis (MN): VA Office of Research and Development, Health Services Research and Development Service; 2011.

17. Performance of traumatic brain injury specific ocular health and visual functioning examinations for polytrauma rehabilitation center patients. VHA directive 2008-065. Washington (DC): Department of Veterans Affairs; 2008 [updated 2008 Oct 20; cited 2012 August 22]. Available from: http://www1.va.gov/vhapublications/ViewPublication.asp? pub ID $=1783$

18. Rand Corporation [Internet]. Delphi method. Santa Monica (CA): Rand Corporation; 2013 [updated 2011 Jan 29; cited 2012 May 31]. Available from: http://www.rand.org/topics/ delphi-method.html

19. Williams PL, Webb C. The Delphi technique: a methodological discussion. J Adv Nurs. 1994;19(1):180-86. 


\section{[PMID:8138622]}

http://dx.doi.org/10.1111/j.1365-2648.1994.tb01066.x

20. Dalkey N, Helmer O. An experimental application of the Delphi method to the use of experts. Manage Sci. 1963; 9(3):458-67. http://dx.doi.org/10.1287/mnsc.9.3.458

21. Keeney S, Hasson F, McKenna H. Consulting the oracle: ten lessons from using the Delphi technique in nursing research. J Adv Nurs. 2006;53(2):205-12.

[PMID:16422719]

http://dx.doi.org/10.1111/j.1365-2648.2006.03716.x

22. Keeney S, Hasson F, McKenna HP. A critical review of the Delphi technique as a research methodology for nursing. Int J Nurs Stud. 2001;38(2):195-200. [PMID:11223060] http://dx.doi.org/10.1016/S0020-7489(00)00044-4

23. Hasson F, Keeney S, McKenna H. Research guidelines for the Delphi survey technique. J Adv Nurs. 2000;32(4): 1008-15. [PMID:11095242]

24. Campbell SM, Cantrill JA, Roberts D. Prescribing indicators for UK general practice: Delphi consultation study. BMJ. 2000;321(7258):425-28. [PMID:10938052] http://dx.doi.org/10.1136/bmj.321.7258.425

25. Douglas RS, Tsirbas A, Gordon M, Lee D, Khadavi N, Garneau HC, Goldberg RA, Cahill K, Dolman PJ, Elner V, Feldon S, Lucarelli M, Uddin J, Kazim M, Smith TJ, Khanna D; International Thyroid Eye Disease Society. Development of criteria for evaluating clinical response in thyroid eye disease using a modified Delphi technique. Arch Ophthalmol. 2009;127(9):1155-60. [PMID:19752424] http://dx.doi.org/10.1001/archophthalmol.2009.232

26. Powell C. The Delphi technique: myths and realities. J Adv Nurs. 2003;41(4):376-82. [PMID:12581103] http://dx.doi.org/10.1046/j.1365-2648.2003.02537.x

27. Fink A, Kosecoff J, Chassin M, Brook RH. Consensus methods: characteristics and guidelines for use. Am J Public Health. 1984;74(9):979-83. [PMID:6380323] http://dx.doi.org/10.2105/AJPH.74.9.979

28. Schoenbaum SC, McNeil BJ, Kavet J. The swine-influenza decision. N Engl J Med. 1976;295(14):759-65.

[PMID:822331]

http://dx.doi.org/10.1056/NEJM197609302951405

29. Milholland AV, Wheeler SG, Heieck JJ. Medical assessment by a Delphi group opinion technic. N Engl J Med. 1973;288(24):1272-75. [PMID:4703316] http://dx.doi.org/10.1056/NEJM197306142882405

30. Ferri CP, Prince M, Brayne C, Brodaty H, Fratiglioni L, Ganguli M, Hall K, Hasegawa K, Hendrie H, Huang Y, Jorm A, Mathers C, Menezes PR, Rimmer E, Scazufca M; Alzheimer's Disease International. Global prevalence of dementia: a Delphi consensus study. Lancet. 2005;366(9503): 2112-17. [PMID:16360788] http://dx.doi.org/10.1016/S0140-6736(05)67889-0
31. Stelmack J, Szlyk JP, Stelmack T, Babcock-Parziale J, Demers-Turco P, Williams RT, Massof RW. Use of Rasch person-item map in exploratory data analysis: a clinical perspective. J Rehabil Res Dev. 2004;41(2):233-41.

[PMID: 15558377]

http://dx.doi.org/10.1682/JRRD.2004.02.0233

32. Wilkinson CP, Ferris FL 3rd, Klein RE, Lee PP, Agardh CD, Davis M, Dills D, Kampik A, Pararajasegaram R, Verdaguer JT; Global Diabetic Retinopathy Project Group. Proposed international clinical diabetic retinopathy and diabetic macular edema disease severity scales. Ophthalmology. 2003;110(9):1677-82. [PMID:13129861] http://dx.doi.org/10.1016/S0161-6420(03)00475-5

33. Myint J, Edgar DF, Kotecha A, Crabb DP, Lawrenson JG. Development of a competency framework for optometrists with a specialist interest in glaucoma. Eye (Lond). 2010;24(9):1509-14. [PMID:20467448]

http://dx.doi.org/10.1038/eye.2010.62

34. Tobacman JK, Zimmerman B, Lee P, Hilborne L, Kolder $\mathrm{H}$, Brook RH. Visual acuity following cataract surgeries in relation to preoperative appropriateness ratings. Med Decis Making. 2003;23(2):122-30. [PMID:12693874] http://dx.doi.org/10.1177/0272989X03251241

35. Kingston J, Katsaros J, Vu Y, Goodrich GL. Neurological vision rehabilitation: description and case study. $\mathrm{J}$ Vis Impair Blind. 2010;104(10):603-12.

36. Goss DA. Clinical accommodation testing. Curr Opin Ophthalmol. 1992;3(1):78-82. [PMID:10149307] http://dx.doi.org/10.1097/00055735-199202000-00011

37. Peterson MC, Holbrook JH, Von Hales D, Smith NL, Staker LV. Contributions of the history, physical examination, and laboratory investigation in making medical diagnoses. West J Med. 1992;156(2):163-65. [PMID:1536065]

38. Hampton JR, Harrison MJ, Mitchell JR, Prichard JS, Seymour C. Relative contributions of history-taking, physical examination, and laboratory investigation to diagnosis and management of medical outpatients. BMJ. 1975;2(5969): 486-89. [PMID:1148666] http://dx.doi.org/10.1136/bmj.2.5969.486

39. Goodrich GL, Kirby J, Cockerham G, Ingalla SP, Lew HL. Visual function in patients of a polytrauma rehabilitation center: A descriptive study. J Rehabil Res Dev. 2007;44(7): 929-36. [PMID:18075950] http://dx.doi.org/10.1682/JRRD.2007.01.0003

40. Capó-Aponte JE, Urosevich TG, Temme LA, Tarbett AK, Sanghera NK. Visual dysfunctions and symptoms during the subacute stage of blast-induced mild traumatic brain injury. Mil Med. 2012;177(7):804-13. [PMID:22808887]

41. Hokoda SC. General binocular dysfunctions in an urban optometry clinic. J Am Optom Assoc. 1985;56(7):560-62. [PMID:4020010] 
42. Lara F, Cacho P, García A, Megías R. General binocular disorders: prevalence in a clinic population. Ophthalmic Physiol Opt. 2001;21(1):70-74. [PMID:11220042] http://dx.doi.org/10.1046/j.1475-1313.2001.00540.x

43. Cohen Y, Segal O, Barkana Y, Lederman R, Zadok D, Pras E, Morad Y. Correlation between asthenopic symptoms and different measurements of convergence and reading comprehension and saccadic fixation eye movements. Optometry. 2010;81(1):28-34. [PMID:20004875] http://dx.doi.org/10.1016/j.optm.2008.10.019

44. Thiagarajan P, Ciuffreda KJ, Ludlam DP. Vergence dysfunction in mild traumatic brain injury (mTBI): a review. Ophthalmic Physiol Opt. 2011;31(5):456-68.

[PMID:21410499]

http://dx.doi.org/10.1111/j.1475-1313.2011.00831.x

45. Borsting E, Rouse MW, De Land PN. Prospective comparison of convergence insufficiency and normal binocular children on CIRS symptom surveys. Convergence Insufficiency and Reading Study (CIRS) group. Optom Vis Sci. 1999;76(4):221-28. [PMID:10333184]

46. Scheiman M, Mitchell GL, Cotter S, Cooper J, Kulp M, Rouse M, Borsting E, London R, Wensveen J; Convergence Insufficiency Treatment Trial Study Group. A randomized clinical trial of treatments for convergence insufficiency in children. Arch Ophthalmol. 2005;123(1): 14-24. [PMID:15642806]

http://dx.doi.org/10.1001/archopht.123.1.14

47. Cohen M, Groswasser Z, Barchadski R, Appel A. Convergence insufficiency in brain-injured patients. Brain Inj. 1989;3(2):187-91. [PMID:2471568] http://dx.doi.org/10.3109/02699058909004551

48. Wold JE, Hu A, Chen S, Glasser A. Subjective and objective measurement of human accommodative amplitude. J Cataract Refract Surg. 2003;29(10):1878-88. [PMID:14604706] http://dx.doi.org/10.1016/S0886-3350(03)00667-9

49. Ciuffreda KJ, Ludlam DP. Objective diagnostic and interventional vision test protocol for the mild traumatic brain injury population. Optometry. 2011;82(6):337-39. [PMID:21616461] http://dx.doi.org/10.1016/j.optm.2011.03.006
50. Murphy MK, Black NA, Lamping DL, McKee CM, Sanderson CF, Askham J, Marteau T. Consensus development methods, and their use in clinical guideline development. Health Technol Assess. 1998;2(3):i-iv, 1-88. [PMID:9561895]

51. Campbell SM, Hann M, Roland MO, Quayle JA, Shekelle PG. The effect of panel membership and feedback on ratings in a two-round Delphi survey: results of a randomized controlled trial. Med Care. 1999;37(9):964-68.

[PMID:10493474] http://dx.doi.org/10.1097/00005650-199909000-00012

52. Hoge CW, Goldberg HM, Castro CA. Care of war veterans with mild traumatic brain injury-flawed perspectives. N Engl J Med. 2009;360(16):1588-91. [PMID:19369664] http://dx.doi.org/10.1056/NEJMp0810606

53. Kraus MF, Little DM, Donnell AJ, Reilly JL, Simonian N, Sweeney JA. Oculomotor function in chronic traumatic brain injury. Cogn Behav Neurol. 2007;20(3):170-78. [PMID:17846516] http://dx.doi.org/10.1097/WNN.0b013e318142badb

Submitted for publication October 12, 2012. Accepted in revised form January 16, 2013.

This article and any supplementary material should be cited as follows:

Goodrich GL, Martinsen, GL, Flyg HM, Kirby J, Asch SM, Brahm KD, Brand JM, Cajamarca D, Cantrell JL, Chong T, Dziadul JA, Hetrick BJ, Huang MA, Ihrig C, Ingalla SP, Meltzer BR, Rakoczy CM, Rone A, Schwartz E, Shea JE. Development of a mild traumatic brain injury-specific vision screening protocol: A Delphi study. J Rehabil Res Dev. 2013;50(6):757-68. http://dx.doi.org/10.1682/JRRD.2012.10.0184

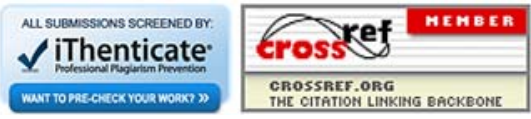

